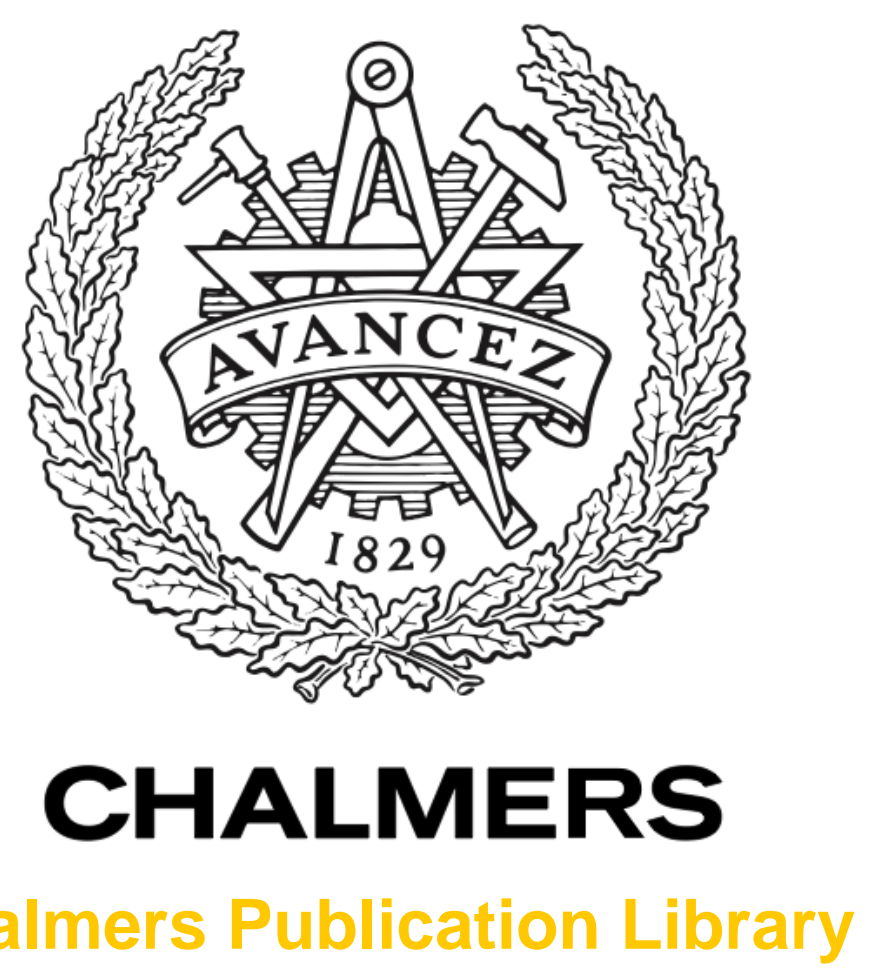

\title{
Catalytic depolymerisation and conversion of Kraft lignin into liquid products using near-critical water
}

This document has been downloaded from Chalmers Publication Library (CPL). It is the author's version of a work that was accepted for publication in:

Journal of Supercritical Fluids (ISSN: 0896-8446)

Citation for the published paper:

Nguyen, T. ; Maschietti, M. ; Belkheiri, T. et al. (2014) "Catalytic depolymerisation and conversion of Kraft lignin into liquid products using near-critical water". Journal of

Supercritical Fluids, vol. 86 pp. 67-75.

http://dx.doi.org/10.1016/j.supflu.2013.11.022

Downloaded from: http://publications.lib.chalmers.se/publication/195936

Notice: Changes introduced as a result of publishing processes such as copy-editing and formatting may not be reflected in this document. For a definitive version of this work, please refer to the published source. Please note that access to the published version might require a subscription.

Chalmers Publication Library (CPL) offers the possibility of retrieving research publications produced at Chalmers University of Technology. It covers all types of publications: articles, dissertations, licentiate theses, masters theses, conference papers, reports etc. Since 2006 it is the official tool for Chalmers official publication statistics. To ensure that Chalmers research results are disseminated as widely as possible, an Open Access Policy has been adopted.

The CPL service is administrated and maintained by Chalmers Library. 


\title{
Catalytic depolymerisation and conversion of Kraft lignin into liquid products using near-critical water
}

\author{
Thi Dieu Huyen Nguyen a ${ }^{\mathrm{a}}$, Marco Maschietti ${ }^{\mathrm{a}, *}$, Tallal Belkheiri ${ }^{\mathrm{b}}$, Lars-Erik Åmand ${ }^{\mathrm{b}}$, \\ Hans Theliander ${ }^{\mathrm{a}}$, Lennart Vamling ${ }^{\mathrm{b}}$, Lars Olausson ${ }^{\mathrm{c}}$, Sven-Ingvar Andersson ${ }^{\mathrm{a}}$ \\ a Chalmers University of Technology, Department of Chemical and Biological Engineering, SE-412 96 Gothenburg, Sweden \\ b Chalmers University of Technology, Department of Energy and Environment, SE-412 96 Gothenburg, Sweden \\ ${ }^{c}$ Metso Power AB, Box 8734, SE-402 75 Gothenburg, Sweden
}

\section{A R T I C L E I N F O}

\section{Article history:}

Received 4 October 2013

Received in revised form

26 November 2013

Accepted 27 November 2013

\section{Keywords:}

Lignin

LignoBoost

Catalytic conversion

Hydrothermal conversion

Bio-oil

Near-critical water

\begin{abstract}
A B S T R A C T
A high-pressure pilot plant was developed to study the conversion of LignoBoost Kraft lignin into bio-oil and chemicals in near-critical water $\left(350^{\circ} \mathrm{C}, 25 \mathrm{MPa}\right)$. The conversion takes place in a continuous fixedbed catalytic reactor $\left(500 \mathrm{~cm}^{3}\right)$ filled with $\mathrm{ZrO}_{2}$ pellets. Lignin (mass fraction of approximately 5.5\%) is dispersed in an aqueous solution containing $\mathrm{K}_{2} \mathrm{CO}_{3}$ (from $0.4 \%$ to $2.2 \%$ ) and phenol (approximately $4.1 \%$ ). The feed flow rate is $1 \mathrm{~kg} / \mathrm{h}$ (reactor residence time $11 \mathrm{~min}$ ) and the reaction mixture is recirculated internally at a rate of approximately $10 \mathrm{~kg} / \mathrm{h}$. The products consist of an aqueous phase, containing phenolic chemicals, and a bio-oil, showing an increased heat value $(32 \mathrm{MJ} / \mathrm{kg}$ ) with respect to the lignin feed. The 1-ring aromatic compounds produced in the process are mainly anisoles, alkylphenols, guaiacols and catechols: their overall yield increases from $17 \%$ to $27 \%$ (dry lignin basis) as $\mathrm{K}_{2} \mathrm{CO}_{3}$ is increased.
\end{abstract}

(C) 2013 Elsevier B.V. All rights reserved.

\section{Introduction}

After cellulose, lignin is the second most abundant natural organic polymer found on earth, being the first among those composed of aromatic units (phenylpropane monomer units). A vast amount of lignin is extracted from wood in the Kraft pulping process and thereby ends up in the black liquor. Today this liquor is concentrated by means of evaporation and used as fuel in the production of heat and power for the pulping process itself. So far only a small proportion of the lignin (approx. 1\%) has been used as a raw material in the production of materials and chemicals with a higher value than fuel. A new process called "LignoBoost" has recently been developed with the aim of extracting part of the lignin in the black liquor at a high purity level, thus exploiting the energy surplus of Kraft pulp mills. The LignoBoost process has recently gained commercial status; therefore, in years to come, a huge amount of LignoBoost Kraft lignin is expected to be available for valorisation [1,2].

Lignin is an amorphous biopolymer whose primary aromatic units are linked together randomly by different types of ether

\footnotetext{
* Corresponding author. Tel.: +46 031772 2989; fax: +46 0317722995.

E-mail addresses: marcom@chalmers.se, maschietti@hotmail.com (M. Maschietti).
}

$(\mathrm{C}-\mathrm{O}-\mathrm{C})$ and carbon-carbon $(\mathrm{C}-\mathrm{C})$ bonds [3]. Its chemical structure suggests that this biopolymer could be a good source of liquid fuel additive and commercially important chemicals, phenolics in particular, if it could be broken down into smaller molecular units that retain the oxy-aromatic nature $[4,5]$. In the quest to reach this goal, several processes for depolymerisation and conversion of different types of lignin have been investigated for decades, such as pyrolysis, which uses thermal treatment in the absence of air, hydrogenolysis, which is a thermal process in the presence of gaseous hydrogen or of a hydrogen-donating solvent, and oxidative cracking, which occurs in the presence of oxidising agents such as hydrogen peroxide [5].

More recently, it has been demonstrated that lignin can be depolymerised and converted into smaller molecular units in supercritical water. This process was, for example, carried out by Saisu et al. [6] at $400^{\circ} \mathrm{C}$ without using a catalyst: they found that the yield of monomeric phenolic compounds was lower than expected. This was probably due to the re-polymerisation of monomers, resulting in the formation of char. Many authors [6-8] have however found that adding phenol to the reacting system decreases the formation of char. The effect of phenol in particular was studied in detail by Fang et al. [8], who decomposed lignin in supercritical water at temperatures between $400^{\circ} \mathrm{C}$ and $600^{\circ} \mathrm{C}$ in a microreactor. More specifically, according to these authors, phenol allows the system to become homogeneous at the reaction conditions and prevents the re-polymerisation reactions, which lead to char being 
formed. The fact that the addition of phenol was found able to prevent the formation of char is also very much in line with the results obtained by Aida et al. [9], who carried out the depolymerisation of coal in phenol-water mixtures at $400^{\circ} \mathrm{C}$.

One promising alternative for processes in supercritical water is the catalytic conversion in near-critical water, where the bonds of the lignin network are cleaved at mild temperatures (i.e. $280-370^{\circ} \mathrm{C}$ ), thus allowing the aromatic nature of the building block molecules to be retained to a greater extent. In this regard, some authors have focused on lignin depolymerisation and conversion in near-critical water using strong bases as a catalyst [10-13], but high yields of heavy fractions and char are reported. In another research work, Karagöz et al. [14] compared the effect of different base solutions (i.e. $\mathrm{K}_{2} \mathrm{CO}_{3}, \mathrm{KOH}, \mathrm{NaOH}$ and $\mathrm{Na}_{2} \mathrm{CO}_{3}$ ) in the hydrothermal treatment of wood biomass at $280{ }^{\circ} \mathrm{C}$; they reported $\mathrm{K}_{2} \mathrm{CO}_{3}$ as being the most efficient catalyst in increasing the liquid-product yield and decreasing the solid residue. In a following work on the same topic, Karagöz et al. [15] observed that an increase in the concentration of $\mathrm{K}_{2} \mathrm{CO}_{3}$ leads to a decrease in char formation and an increase in liquid-product yield, together with an increase in catechol and a decrease of guaiacol in the water-soluble products. These results on the effect of $\mathrm{K}_{2} \mathrm{CO}_{3}$ are in line with those reported by Bhaskar et al. [16] pertaining to the same process applied to different wood biomasses.

Moreover, Andersen [17,18] disclosed a process whereby an organic material is converted into small molecular units operating in water at temperatures from $270^{\circ} \mathrm{C}$ to $380^{\circ} \mathrm{C}$, pressures from 15.2 MPa to $27.4 \mathrm{MPa}$ and in the presence of the catalyst $\mathrm{ZrO}_{2}$. In these patents, the important role of $\mathrm{ZrO}_{2}$ in reducing the formation of char is emphasised. Furthermore, Hammerschmidt et al. [19] and Toor et al. [20] carried out the catalytic conversion of different types of sludge waste streams from food industry and machinery work [19] or distiller's grain with solubles [20], operating in near-critical water $\left(>300^{\circ} \mathrm{C}, 25 \mathrm{MPa}\right)$ in the presence of both $\mathrm{K}_{2} \mathrm{CO}_{3}$ and $\mathrm{ZrO}_{2}$ catalysts. These works show not only the feasibility of the conversion of different slurries of organic substances using this catalytic system but also good results in terms of oil yield. Since these applications are very different compared to conversion of pure lignin, it is of interest to test the feasibility of a process based on $\mathrm{ZrO}_{2}+\mathrm{K}_{2} \mathrm{CO}_{3}$ on this peculiar biomass. Furthermore, the previous attempts of converting lignin in near-critical or supercritical water were carried out on small laboratory batch units and they typically led to high amount of solid residues, if phenol was not added to the reacting system. A high production of solid residues may lead to serious operational problems in the development of the process to a continuous mode of operation on a large scale.

Therefore, the objective of the present work is to study the feasibility of a continuous process for converting LignoBoost Kraft lignin into transportation bio-fuels and aromatic chemicals in near-critical water $\left(350^{\circ} \mathrm{C}, 25 \mathrm{MPa}\right)$, using $\mathrm{ZrO}_{2}$ and $\mathrm{K}_{2} \mathrm{CO}_{3}$ as the catalysts and phenol as the co-solvent. The set-up of the plant and the development of the analytical procedure of the reaction products are described in details. In addition, preliminary results focusing on the effect of the $\mathrm{K}_{2} \mathrm{CO}_{3}$ mass fraction are presented and discussed.

\section{Materials and methods}

\subsection{Materials}

The Kraft lignin used as the feed material in this work is from softwood and is produced in the LignoBoost demonstration plant in Bäckhammar (Sweden). The heterogeneous catalyst used in the reactor is made of zirconia $\left(\mathrm{ZrO}_{2}\right)$ pellets (Harshaw Chemie BV, length: $3 \mathrm{~mm}$, diameter: $3 \mathrm{~mm}$, BET surface area $48 \mathrm{~m}^{2} / \mathrm{g}$ ). The potassium carbonate $\left(\mathrm{K}_{2} \mathrm{CO}_{3}, \geq 99.5 \%\right)$ used as the homogeneous cocatalyst and the phenol (crystallised, $\geq 99.5 \%$ ) used as the co-solvent are from Scharlau, as is the $1 \mathrm{~mol} / \mathrm{L}$ hydrochloric acid $(\mathrm{HCl})$ used in the analytical procedure of the aqueous phase. Sigma-Aldrich is the source of the following: anisole ( $\geq 99.65 \%)$, phenol ( $\geq 99.5 \%)$, o$\operatorname{cresol}(\geq 99 \%)$, m-cresol (99\%), p-cresol ( $\geq 99.0 \%)$, guaiacol ( $\geq 98.0 \%$ ), catechol ( $\geq 99 \%$ ) and syringol ( $\geq 98.5 \%)$, used as analytical standards, Hydranal-Composite 5 and methanol (puriss. p.a. $\geq 99.8 \%$ ), used for Karl Fischer titration, tetrahydrofuran (THF, $\geq 99.9 \%$ ) and diethyl ether (DEE, $\geq 99.9 \%$ ), used as solvents in the analytical protocol. All chemicals were used as provided, without further purification.

\subsection{Apparatus and procedure}

A schematic diagram of the laboratory plant used is shown in Fig. 1. Prior to the start of the experimental run the system is heated up and pressurised to operating conditions, keeping a continuous flow of deionised (DI) water. During the run the feed, composed of lignin, $\mathrm{K}_{2} \mathrm{CO}_{3}$, phenol and DI water, is continuously pumped by a high-pressure diaphragm pump (Lewa) at a flow rate of $1 \mathrm{~kg} / \mathrm{h}$, measured by a mass flow-metre (Endress and Hauser, Promass). The lignin slurry is prepared by crushing lignin manually before dispersing it in a solution of $\mathrm{K}_{2} \mathrm{CO}_{3}$ in DI water. The actual dispersion procedure is performed using an Ultra Turrax disperser (IKA WERK T 45/N), operating at room temperature for approx. $5 \mathrm{~min}$. The feed is made by mixing the prepared lignin slurry with phenol; it is stored in a $10 \mathrm{~L}$ feed tank equipped with an impeller, where it is kept at $40^{\circ} \mathrm{C}$. Prior to entering the reactor, the feed is heated to $80^{\circ} \mathrm{C}$ in the electric preheater and is mixed with the recirculation stream of reaction products provided by the high-temperature high-pressure recirculation pump. The recycle to feed ratio is kept at approximately 10 , and is estimated by measuring temperatures before and after the mixing point and then applying an energy balance. The recirculation allows the fresh feed to be heated rapidly and mixed before coming into contact with the heterogeneous catalyst in the reactor. There is a second electric heater installed in the inlet line of the reactor. The reaction mixture comes into contact with the solid catalyst whilst flowing upwards in the $500 \mathrm{~cm}^{3}$ fixedbed reactor (Parr 4575; height: $171 \mathrm{~mm}$, internal diameter: $61 \mathrm{~mm}$ ), which is composed of Inconel 600 in the high-temperature parts and equipped with an electrical heating jacket. The free volume of the reactor charged with the catalyst is $294 \mathrm{~cm}^{3}$. At reaction conditions $\left(350^{\circ} \mathrm{C}, 25 \mathrm{MPa}\right.$ ), the density of water is $625 \mathrm{~kg} / \mathrm{m}^{3}$ (NIST data base) and the reactor residence time $(\tau)$ is approximately $11 \mathrm{~min}$.

The reaction products are cooled down and depressurised to ambient conditions. Two pressure control valves are used for controlling the system pressure and for depressurising the reaction products. These valves are in parallel so that they can be switched over from one to the other in case the valve in operation becomes congested by solid particles. The liquid products are collected continuously in sampling bottles for analysis. Each sampling bottle is used to collect the liquid products corresponding to approximately $45 \mathrm{~min}$ of operation. The $\mathrm{pH}$ of the liquid products of each sampling bottle is measured through a pH-metre (Jenway, 370) equipped with a glass electrode (Jenway, 924005), using a 2-point calibration with standard buffer solutions. Gas samples were not taken in the runs that were carried out since no significant amount of gas was collected in a gas sampling bag (Tedlar sample bag, SKC, USA) placed downstream of the sampling bottle, on the output line exiting the cap of the bottle. Auxiliary lines for cleaning the apparatus in between the runs and safety systems are also installed.

The observation was made that the visual appearance of the products in the sampling bottles changes progressively during the start-up period and shows a progressive darkening: the exception was a single run without lignin in the feed (see Section 2.3), in which the products consisted of a homogeneous liquid phase showing a 


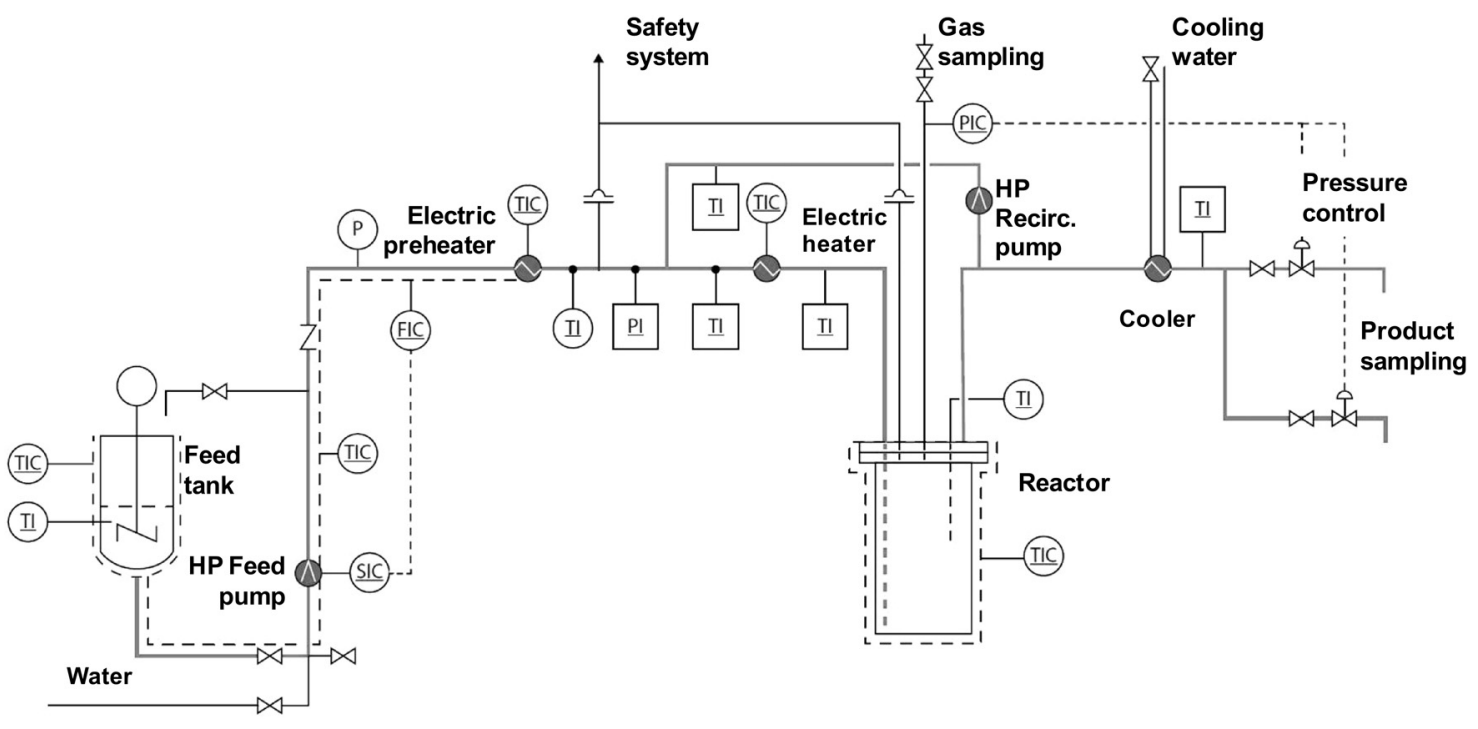

Fig. 1. Schematic diagram of the pilot plant.

Table 1

Feed data of the mass fraction (\%) of each component in Runs A-E and feed pH.

\begin{tabular}{llllll}
\hline Feed data & $\mathrm{A}$ & $\mathrm{B}$ & $\mathrm{C}$ & $\mathrm{D}$ & $\mathrm{E}$ \\
\hline $\mathrm{K}_{2} \mathrm{CO}_{3}(\%)$ & 0.4 & 1.0 & 1.6 & 2.2 & 1.9 \\
Dry lignin (\%) & 5.6 & 5.5 & 5.5 & 5.4 & 0 \\
Phenol (\%) & 4.1 & 4.1 & 4.1 & 4.0 & 4.7 \\
$\mathrm{pH}_{\mathrm{f}}$ & 7.9 & 8.8 & 9.1 & 9.3 & 9.5 \\
\hline
\end{tabular}

steady appearance from the beginning. After a period of approximately $2 \mathrm{~h}$ from the start, the operating parameters of the plant, the visual appearance of the products and the $\mathrm{pH}$ of the aqueous phase in the sampling bottles kept steady in all runs. In the case of the runs with lignin in the feed (see Section 2.3), the $\mathrm{pH}$ of the aqueous phase in the sampling bottles varied of about $0.5-0.7 \mathrm{pH}$ units during the first $2 \mathrm{~h}$, while it kept constant $( \pm 0.1)$ afterward. The runs that were carried out lasted for around 4 h, i.e. the steady state period was kept for approx. $2 \mathrm{~h}$ before the shutdown operations began. After the end of each experimental run the plant is cleaned, the reactor disassembled and char deposited on the catalyst measured.

Several liquid product samples were taken during the steadystate operation. When lignin is fed to the system the samples were found to consist of two distinct liquid phases: aqueous and oil. These were separated by means of centrifugation (Thermo Fisher Scientific, Heraeus Megafuge 40R) operating at $492 \mathrm{rad} / \mathrm{s}$ for $3 \mathrm{~h}$ at $25^{\circ} \mathrm{C}$. This process gives a fairly transparent aqueous phase with a colour ranging from yellowish to dark green (depending on the mass fraction of $\mathrm{K}_{2} \mathrm{CO}_{3}$ in the feed) and a high-viscosity black oil phase (lignin-oil) that is heavier than the aqueous phase. In order to obtain larger single samples for the analytical procedures, all of the aqueous samples were mixed into one single aqueous sample; the same was done with the oil samples. These samples are representative of an average of the steady-state conditions. Because of its high viscosity, the oil was dissolved in THF in order to achieve complete recovery of it, as well as to facilitate the mixing of the samples from different bottles. THF was then evaporated in a rotary vacuum evaporator (Büchi, R) operating at temperatures never exceeding $35^{\circ} \mathrm{C}$.

\subsection{Experimental conditions}

Table 1 reports the operating conditions of the experimental runs. In all runs, the reactor temperature and the pressure were kept at $350^{\circ} \mathrm{C}$ and $25 \mathrm{MPa}$, respectively. In four experimental runs
(A-D), the mass fraction of $\mathrm{K}_{2} \mathrm{CO}_{3}$ in the feed was varied (from $0.4 \%$ to $2.2 \%$ ) in order to evaluate the effect of the mass fraction of the co-catalyst on the process. In these runs the phenol to dry lignin ratio was in the range of $0.73-0.75$ (mass basis). In the fifth run (E), however, the feed was prepared without lignin, with only $\mathrm{K}_{2} \mathrm{CO}_{3}$ and phenol being dissolved in DI water.

\subsection{Analytical methods}

\subsubsection{Characterisation of lignin}

The moisture content of the lignin was measured prior to each experimental run by a moisture analyser (Sartorius MA30) operating at $130^{\circ} \mathrm{C}$ employing the auto-stabilisation method. The elemental composition, ash content and heat value of this lignin were all analyzed at SP Sveriges Tekniska Forskningsinstitut (Borås, Sweden). The carbon, hydrogen and nitrogen content was measured according to the method SS-EN 15104, the sulphur and chlorine content according to the methods SS-EN 15289 and SS-EN 15289 A, respectively and the ash content and heat value according to the methods SS-EN 14775 and SS-EN 14918, respectively. The mass fraction of aromatic and aliphatic groups was determined using a ${ }^{13} \mathrm{C}$ NMR (Varian NMR Spectrometer).

\subsubsection{Analysis of the aqueous phase}

The Total Carbon (TC) and Total Organic Carbon (TOC) of the aqueous phase samples obtained after centrifugation were measured at SP Sveriges Tekniska Forskningsinstitut (Borås, Sweden) according to the SS-EN 1484 method. The relative uncertainty (95\% confidence interval) of the TOC measurement is $8 \%$. In addition, detailed identification of the water-soluble organics present in the aqueous phase was carried out by means of Gas Chromatography (GC) coupled with Mass Spectrometry (MS), according to the procedure described below.

Approximately $50 \mathrm{~g}$ of the aqueous phase are withdrawn and acidified to $\mathrm{pH} 1.5-2.0$ by adding $\mathrm{HCl}$. In the runs with lignin in the feed (Runs A-D) it was observed that acidification led to further clarification of the aqueous phase giving rise, in turn, to the separation of very small amounts of additional phases: some heavier black drops at the bottom and a lighter yellowish phase at the top. These additional phases were, however, not analyzed because the amounts were very small. On the other hand, the gas that is released from the solution during acidification is quantified gravimetrically. 


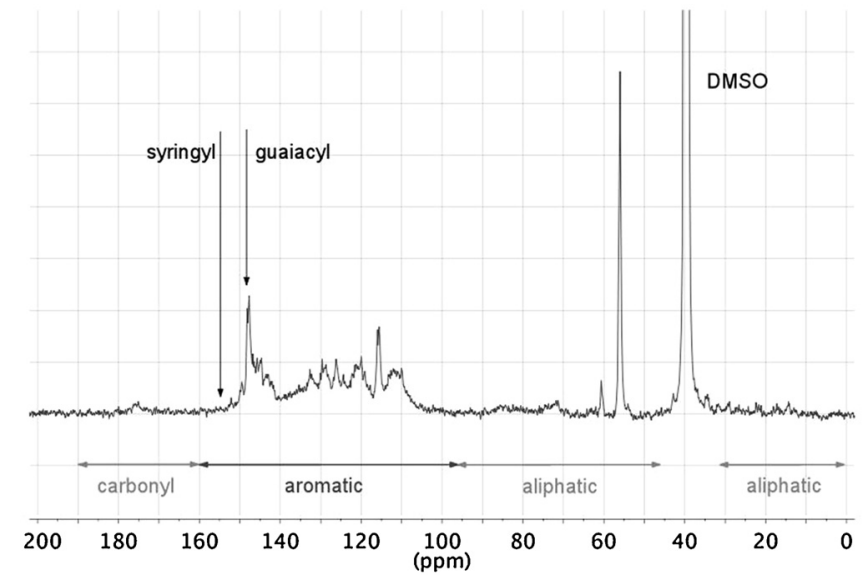

Fig. 2. ${ }^{13} \mathrm{C}$ NMR spectrum of the LignoBoost Kraft lignin used in the feed.

The identification and quantitation of the water-soluble organics is carried out as follows: approximately $10 \mathrm{~g}$ of the acidified aqueous phase are withdrawn, filtered through a $0.45 \mu \mathrm{m}$ syringe filter, mixed with a known amount of internal standard and then extracted with DEE in a separating funnel, with a solvent to feed ratio $(\mathrm{S} / \mathrm{F})$ equal to 1 . Since syringol is not an aromatic unit present in softwood lignin (see Fig. 2) it is not produced in the reaction; it is nevertheless similar to the reaction products and was thus selected for use as the internal standard (IST).

The organic extracts are analyzed using a gas chromatograph (Agilent 7890A) connected to a mass spectrometer (Agilent 5975C) operating in electron ionisation mode. The analytes are separated in a chromatographic column HP-5MS (length: $30 \mathrm{~m}$; internal diameter: $0.25 \mathrm{~mm}$; thickness of stationary phase: $0.25 \mu \mathrm{m}$ ) by injecting $1 \mu \mathrm{L}$ of sample via an autosampler (Agilent 7693A), using helium at $1 \mathrm{~mL} / \mathrm{min}$ as the carrier gas. The injector temperature is set at $300^{\circ} \mathrm{C}$ and the temperature programme of the GC oven is $45^{\circ} \mathrm{C}$ for $2.25 \mathrm{~min}, 2^{\circ} \mathrm{C} / \mathrm{min}$ up to $300^{\circ} \mathrm{C}, 300^{\circ} \mathrm{C}$ for $10 \mathrm{~min}$. The MS source and quadrupole temperatures are set at $250^{\circ} \mathrm{C}$ and $150^{\circ} \mathrm{C}$, respectively. Spectral interpretation is carried out using the NIST MS Search programme (version 2.0) operating on the NIST/EPA/NIH Mass Spectral Database 2011 (NIST 11).

An approximate quantitation of the water-soluble reaction products in the acidified aqueous phase is carried out assuming the following relationship:

$W_{i}=W_{I S T} \cdot \frac{A_{i}}{A_{I S T}}$

where $w$ and $A$ indicate the mass fraction in the acidified aqueous phase and chromatographic peak area, respectively, and the subscripts $i$ and IST refer to the generic analyte $i$ and the internal standard, respectively. The average values of $A_{i}$ and $A_{I S T}$ are calculated from the results of three injections of each sample. The average value of the Relative Standard Deviation (RSD) of the peak area was found to be $7.1 \%$.

\subsubsection{Analysis of the lignin-oil}

The elemental composition, ash content and heat value of the solvent-free lignin-oil were analyzed at SP Sveriges Tekniska Forskningsinstitut (Borås, Sweden). The carbon, hydrogen and nitrogen content was measured according to the method SP 0528, whereas the sulphur content was measured according to the method ASTM D 1552. The ash content and heat value were determined according to the methods SS-EN 6245 and ASTM D 4809, respectively. The lignin-oil produced in the process is soluble in THF.
The water content of the lignin-oil samples was measured through Karl Fischer volumetric titration whereby $1 \mathrm{~g}$ of oil is withdrawn, dissolved in THF (about $20 \mathrm{~g}$ ) and filtered under vacuum using a Büchner funnel equipped with Duran glass filters P2 (nominal maximum pore size $40-100 \mu \mathrm{m}$ ). This filtration step is carried out in order to prevent the accumulation of solid particles in the titrator. A loss of volatiles in the range of $1-7 \%$ (with respect to the mass of diluted oil) was observed during vacuum filtration and assumed to be composed of pure THF (i.e. not water); the oil/THF ratio was then recalculated accordingly. Both the diluted oil and THF used for dilution are titrated in triplicate. The titration of THF is performed in order to take into account the water derived from the solvent used for dilution. The SD of water mass fraction, measured in triplicate titrations, was always below $0.4 \%$. The accuracy of the titration was checked on solutions of water in THF, at water mass fraction of approximately $1 \%$. The Average Absolute Deviation (AAD) on a set of 10 measurements was found to be $0.025 \%$.

THF-insoluble Suspended Solids (SS) in lignin-oil are measured as follows: approximately $2 \mathrm{~g}$ of oil are withdrawn, dissolved in approximately $40 \mathrm{~g}$ of THF and filtered under vacuum through Büchner funnels by means of a two-step process. In the first of these, the diluted oil is filtered on Duran glass filters P2; the prefiltered oil is filtered again through Duran glass filters P4 (nominal maximum pore size $10-16 \mu \mathrm{m}$ ). Prior to filtration, the glass filters are dried in an oven for $1 \mathrm{~h}$ at $105^{\circ} \mathrm{C}$, cooled in a desiccator and weighed. After each filtration step, the filters are washed with THF until the filtrates are clear. They are subsequently dried for $1 \mathrm{~h}$ at $105^{\circ} \mathrm{C}$, cooled in the desiccator and weighed again. The difference between the two weights is the mass of the retained solids. The reproducibility of this method was checked measuring the mass fraction of SS on three oil samples from Run C, obtaining RSD equal to $5.0 \%$.

In addition, the DEE-soluble fraction of lignin-oil is analyzed using GC-MS. Approximately $0.7 \mathrm{~g}$ of oil are withdrawn, extracted with DEE (S/F approximately 43/1) and mixed with a known amount of IST. The oil is partly soluble in DEE and the resulting mixture contains black undissolved drops and solid particles. This mixture is filtered through a $0.45 \mu \mathrm{m}$ syringe filter and a lightyellow clear DEE-rich phase is obtained. This phase is analyzed by means of GC-MS and the main compounds are identified and quantitated according to the same procedure reported in Section 2.4.2. In this case, the average value of the RSD of the peak areas resulted to be $8.8 \%$.

\subsubsection{Quantitation of char}

The reactor is cooled down and disassembled after each run and the catalyst particles are recovered. A portion of the catalyst is sampled, washed with water, dried in oven at $105^{\circ} \mathrm{C}$ for $24 \mathrm{~h}$, cooled down and then weighed. The catalyst pellets are then regenerated by burning off char at $500{ }^{\circ} \mathrm{C}$ for $12 \mathrm{~h}$ before being cooled down and reweighed. In this way, the mass fraction of char on dry catalyst can be determined. Knowledge of the total amount of dry catalyst charged in the reactor prior to the run allows the total amount of char deposited on the catalyst in each experimental run to be calculated.

\section{Results and discussion}

\subsection{Properties of the LignoBoost Kraft lignin used}

The moisture content of the LignoBoost Kraft lignin used was found to be $32.6 \pm 0.4 \%$ (average value $\pm S D$ ), on a set of 13 measurements. The elemental analysis and heat value results are reported in Table 2 on a dry lignin basis. The ${ }^{13} \mathrm{C}$ NMR spectrum is shown in Fig. 2; the mass fraction of the aromatic and aliphatic groups is 
Table 2

Elemental composition (as mass fraction) and higher heat value (HHV) of LignoBoost Kraft lignin used as feed material. The data is reported on a dry lignin basis, together with available uncertainties (95\% confidence interval), relative (rel.) or absolute (abs.). Oxygen is calculated by difference.

\begin{tabular}{lcl}
\hline Elemental composition (\%) & & $\mathrm{U}$ \\
\hline $\mathrm{C}$ & 65.6 & $2 \%$ (rel.) \\
$\mathrm{H}$ & 5.7 & $6 \%$ (rel.) \\
$\mathrm{N}$ & 0.09 & 0.02 (abs.) \\
$\mathrm{S}$ & 1.85 & $10 \%$ (rel.) \\
$\mathrm{Cl}$ & 0.01 & 0.02 (abs.) \\
$\mathrm{Ash}$ & 0.8 & 0.3 (abs.) \\
$\mathrm{O}$ & 26 & - \\
$\mathrm{Na}$ & 0.23 & - \\
$\mathrm{K}$ & 0.07 & - \\
$\mathrm{HHV}(\mathrm{MJ} / \mathrm{kg})$ & 27.67 & 0.39 (abs.) \\
\hline
\end{tabular}

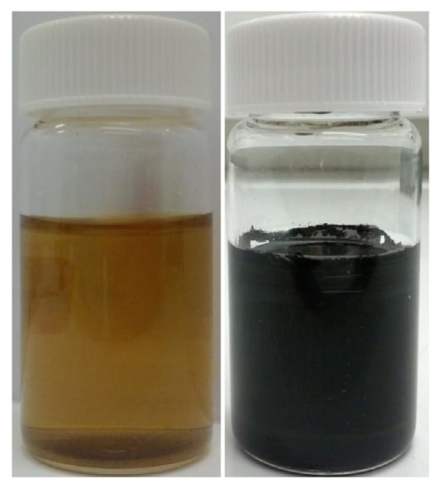

Fig. 3. Typical appearance of the aqueous (left) and oil phases (right) after centrifugation.

Table 3

Steady-state output data of the experiments, Runs A-E. Oil/total is the ratio between the mass flow rate of the output oil and the total mass flow rate at steady-state. $\mathrm{pH}_{\mathrm{a}}$, TC and TOC indicate $\mathrm{pH}$, total carbon and total organic carbon of the aqueous phase after centrifugation.

\begin{tabular}{lccccl}
\hline Steady-state output data & A & B & C & D & E \\
\hline Oil/total (\%) & 5.2 & 5.1 & 5.3 & 5.6 & 0 \\
$\mathrm{pH}_{\mathrm{a}}$ & 7.1 & 7.4 & 8.0 & 8.2 & 9.6 \\
TC $(\mathrm{g} / \mathrm{L})$ & 28 & 27 & 29 & 30 & - \\
TOC $(\mathrm{g} / \mathrm{L})$ & 27 & 26 & 27 & 27 & - \\
\hline
\end{tabular}

$78 \%$ and $22 \%$, respectively. The absence of syringyl groups is consistent with the origin of this lignin, which is from softwood. The mass-average molar mass of LignoBoost softwood lignin produced in Bäckhammar is $3900 \mathrm{~g} / \mathrm{mol}$, with a molar mass dispersity of 5.6 [21].

\subsection{Nature of the liquid products after centrifugation}

After centrifugation, the liquid products are composed of oil and an aqueous phase (see Fig. 3) with the exception of Run E, which had only a homogeneous aqueous phase. The visual appearance of the aqueous phase in Runs A-D ranges from yellowish to dark green as the mass fraction of $\mathrm{K}_{2} \mathrm{CO}_{3}$ in the feed increases. The steadystate output parameters that refer to the oil and aqueous phases are provided in Table 3 along with the TC and TOC of the aqueous phase.

As can be seen, the oil flow rate is between $5 \%$ and $6 \%$ of the total output flow rate. The reaction leads to a decrease in $\mathrm{pH}$, which can be observed by comparing the $\mathrm{pH}$ of the feed given in Table 1 and the $\mathrm{pH}$ of the aqueous phase in Table 3. Also, the $\mathrm{pH}$ of the aqueous phase after centrifugation increases with the mass fraction of $\mathrm{K}_{2} \mathrm{CO}_{3}$ in the feed. In the case of Run $\mathrm{E}$ (no lignin in the feed), on
Table 4

The compounds identified in the acidified aqueous phase. The mass fraction (\%) of the reaction products in the acidified aqueous phase is reported for each of the runs with lignin in the feed. LOD indicates the limit of detection.

\begin{tabular}{|c|c|c|c|c|c|}
\hline & Compound & A & B & $\mathrm{C}$ & $\mathrm{D}$ \\
\hline 1 & Methanol & 0.004 & 0.004 & 0.004 & 0.002 \\
\hline 2 & Acetic acid & 0.004 & 0.005 & 0.006 & 0.006 \\
\hline 3 & 2-Butanone & 0.004 & 0.004 & 0.004 & 0.003 \\
\hline 4 & Propanoic acid & 0.002 & 0.002 & 0.002 & 0.002 \\
\hline 5 & Anisole & 0.001 & 0.001 & 0.001 & 0.034 \\
\hline 6 & Phenol & 2.183 & 2.078 & 1.964 & 1.648 \\
\hline 7 & o-Cresol & 0.061 & 0.064 & 0.067 & 0.073 \\
\hline 8 & $\mathrm{~m} / \mathrm{p}-$ Cresol $^{\mathrm{a}}$ & 0.069 & 0.088 & 0.099 & 0.103 \\
\hline 9 & Guaiacol & 0.094 & 0.067 & 0.054 & 0.038 \\
\hline 10 & 2-Ethylphenol & 0.013 & 0.011 & 0.010 & 0.010 \\
\hline 11 & Dimethylphenol & 0.003 & 0.004 & 0.005 & 0.007 \\
\hline 12 & 4-Ethylphenol & 0.020 & 0.020 & 0.020 & 0.020 \\
\hline 13 & Methylguaiacol & 0.006 & 0.004 & 0.003 & 0.002 \\
\hline 14 & Catechol & 0.144 & 0.166 & 0.193 & 0.196 \\
\hline 15 & 3-Methoxycatechol & 0.005 & 0.005 & 0.006 & 0.002 \\
\hline 16 & 3-Methylcatechol & 0.009 & 0.010 & 0.013 & 0.018 \\
\hline 17 & 4-Ethylguaiacol & 0.004 & 0.001 & $<$ LOD & 0.000 \\
\hline 18 & 4-Methylcatechol & 0.044 & 0.038 & 0.051 & 0.070 \\
\hline 19 & Salicylic acid & $<$ LOD & $<$ LOD & 0.002 & 0.010 \\
\hline 20 & Syringol $^{\mathrm{b}}$ & - & - & - & - \\
\hline 21 & 4-Ethylcatechol & 0.019 & 0.013 & 0.016 & 0.019 \\
\hline $22-24$ & Phenolic dimers & 0.007 & 0.006 & 0.006 & 0.005 \\
\hline \multicolumn{2}{|c|}{ Total mass fraction including phenol } & 2.696 & 2.591 & 2.526 & 2.268 \\
\hline \multicolumn{2}{|c|}{ Total mass fraction excluding phenol } & 0.513 & 0.513 & 0.562 & 0.620 \\
\hline
\end{tabular}

a $\mathrm{p}$-Cresol and $\mathrm{m}$-Cresol elute together.

b Internal standard.

the other hand, the $\mathrm{pH}$ of the product is the same as the $\mathrm{pH}$ of the feed. The concentration of organic carbon in the aqueous phase in Runs A-D is approximately constant and equal to $27 \mathrm{~g} / \mathrm{L}$. Since the density of the aqueous phase is approximately $1000 \mathrm{~kg} / \mathrm{m}^{3}$, this also means that the organic carbon mass fraction in the aqueous phase is about $2.7 \%$. The TC values are slightly higher than the TOC.

\subsection{Aqueous phase}

The mass of gas released during the acidification of the aqueous phase samples increases from $0.1 \%$ to $1.0 \%$ (on the basis of the sample's initial mass) from Run A to Run D, i.e. as the mass fraction of $\mathrm{K}_{2} \mathrm{CO}_{3}$ increases. In Runs $\mathrm{A}-\mathrm{C}$ the mass of gas released is approximately equal to the mass of carbon dioxide expected from carbonates; in the sample from Run D, on the other hand, the gas released exceeds this expected value, which means that additional carbon dioxide and/or other gases must be released in the acidification process. Considering the steady state data of Run D, this difference is found to be approximately $5 \%$ on the basis of the lignin fed into the reactor.

The GC-MS analysis of the aqueous phase produced in Run E shows that phenol is the only solute in the aqueous phase, with the exception of trace amounts of other compounds such as alkylphenols: this is consistent with the profile of the impurities present in the reagent grade of phenol used in the experiments.

Fig. 4 shows a typical total ion current chromatogram (TICC) of the DEE extracts of the acidified aqueous sample obtained when lignin was fed into the system; the structure of the compounds identified is reported, along with number labels. When different isomers are compatible with a peak, the structure reported is an example of one of the possible isomers. For Runs A-D, Table 4 reports the mass fraction of the compounds identified in the acidified aqueous phase together with overall values including, and excluding, phenol. The method used for determining mass fractions can be considered as semi-quantitative, since it is assumed that the response factors of the MS detector and extraction yields from the acidified aqueous phase are the same for each compound. 


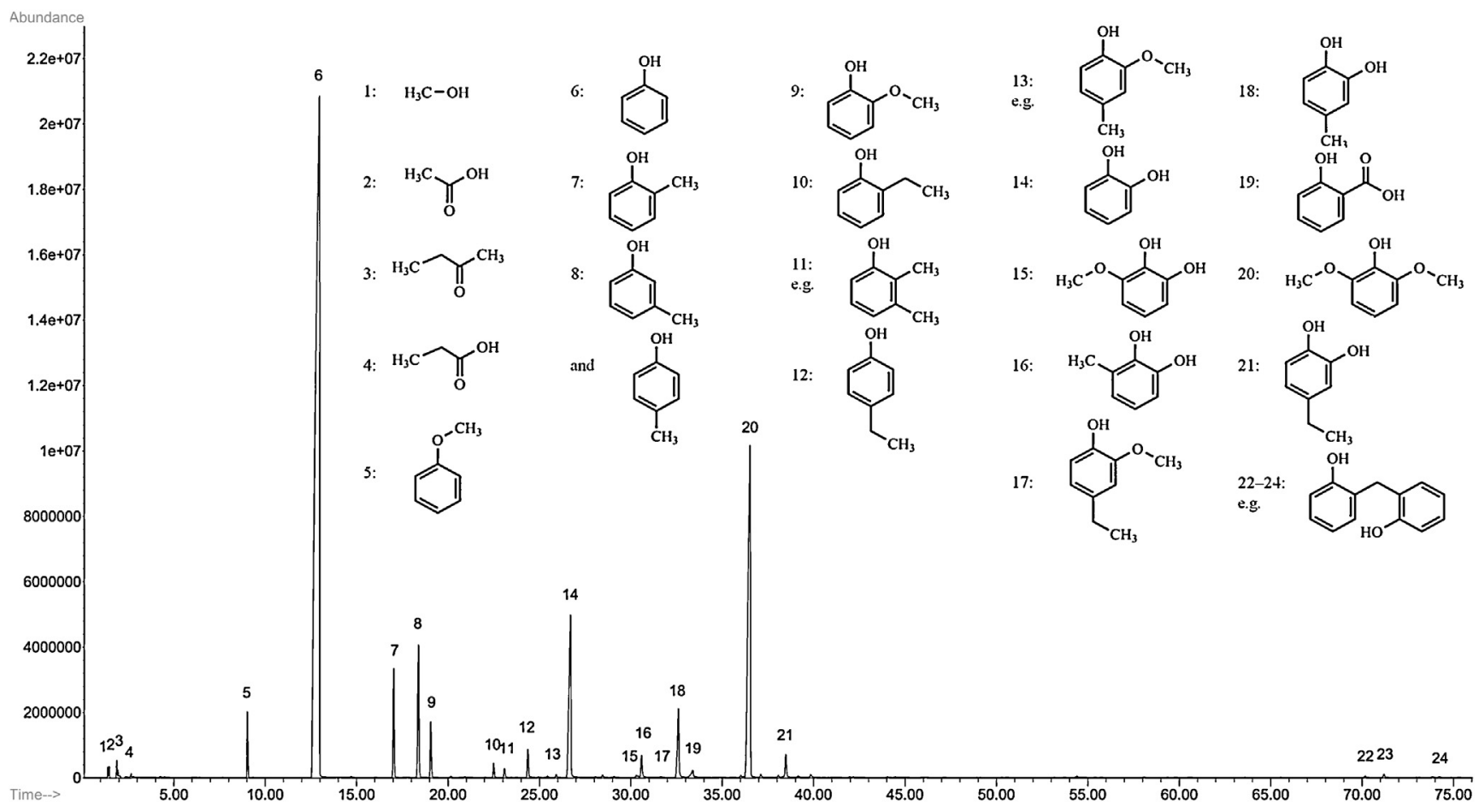

Fig. 4. Typical TICC of the DEE extracts of the acidified aqueous phase (sample from Run D). Peak 20 is the internal standard (syringol).

Table 5

Mass fraction (\%) of the main classes of the compounds in the acidified aqueous phase for each run with lignin in the feed.

\begin{tabular}{lllll}
\hline Class & A & B & C & D \\
\hline Phenol & 2.18 & 2.08 & 1.96 & 1.65 \\
Alkylphenols & 0.17 & 0.19 & 0.20 & 0.21 \\
Guaiacols & 0.10 & 0.07 & 0.06 & 0.04 \\
Catechols & 0.22 & 0.23 & 0.27 & 0.30 \\
\hline
\end{tabular}

Besides phenol, which is used in the feed, the main compounds detected are alkylphenols (e.g. cresols), guaiacols, alkylguaiacols, catechol and alkylcatechols. Alkyl side chains of aromatic rings are of a methyl or ethyl type only. Moreover, a non-phenolic aromatic compound is also found (i.e. anisole), together with small amounts of methanol, acetic acid, 2-butanone, propanoic acid, 3methoxycatechol, salicylic acid and a few phenolic dimers of the type C6-C1-C6 (see Fig. 4). The same set of compounds is found in Runs A-D (i.e. at different mass fractions of $\mathrm{K}_{2} \mathrm{CO}_{3}$ ). Since these compounds are not found in Run E, it can be concluded that those found in the aqueous phase of the runs with lignin in the feed derive from the chemical conversion of lignin.

Furthermore, as the mass fraction of $\mathrm{K}_{2} \mathrm{CO}_{3}$ increases, an increase in the mass fraction of catechols (from $0.22 \%$ to $0.30 \%$ ) and alkylphenols (from $0.17 \%$ to $0.21 \%$ ), together with a decrease in the mass fraction of guaiacols (from $0.10 \%$ to $0.04 \%$ ) is observed (see Table 5). These results are in accordance with previous results reported in the literature $[15,16]$. The total mass fraction of organic compounds (excluding phenol) also increases (from $0.51 \%$ to $0.62 \%$ ) with an increase in the mass fraction of $\mathrm{K}_{2} \mathrm{CO}_{3}$.

\subsection{Lignin-oil}

The oil phase in the liquid obtained in Runs A-D is in the range of $5.1-5.6 \%$, with respect to the total output (see Table 3 ). The oil is separated from the aqueous phase by means of centrifugation and its water content is measured, which is also measured after the THF has been removed by means of vacuum evaporation at
Table 6

Water content and THF-insoluble suspended solids in the lignin-oil. The water mass fraction (\%) in lignin-oil is given before and after vacuum evaporation to remove THF. The suspended solids are given as mass fraction (\%) on a dry lignin-oil basis (i.e. THF-free water-free basis).

\begin{tabular}{lrrrr}
\hline & \multicolumn{1}{c}{ A } & \multicolumn{1}{c}{ B } & \multicolumn{1}{c}{ C } & \multicolumn{1}{c}{ D } \\
\hline Water content before evaporation (\%) & 12.7 & 12.4 & 14.1 & 18.4 \\
Water content after evaporation (\%) & 1.2 & 1.1 & 2.0 & 1.8 \\
Suspended solids (\%) & 0.1 & 1.9 & 22.8 & 22.9 \\
\hline
\end{tabular}

a temperature not exceeding $35^{\circ} \mathrm{C}$. A consistent reduction in the water content is achieved easily during the removal of the solvent, as shown in Table 6.

Furthermore, Table 6 also reports the THF-insoluble SS in the lignin-oil. The SS values are reported as mass fraction on a dry lignin-oil basis (i.e. THF-free water-free basis), referring to the total mass of retained solids, i.e. the sum of the mass of the solids retained on the filters P2 and P4. As can be seen, the THF-insoluble SS are quite low in Runs $A$ and $B$, whereas they increase remarkably when higher mass fractions of $\mathrm{K}_{2} \mathrm{CO}_{3}$ are involved.

After evaporation, the elemental analysis was made of each oil sample and the ash content and heat value were measured; these results are reported on a dry lignin-oil basis in Table 7 . The oil, being partially deoxygenated, is seen here to exhibit a higher content of carbon with respect to dry lignin. A consistent increase in the heat value is also observed ( $+15 \%$ on average). Also, the sulphur content is reduced, on average, from $1.85 \%$ to $0.36 \%$; the ash content in the dry lignin-oil is seen to increase (from $1.0 \%$ to $3.5 \%$ ) as the mass fraction of $\mathrm{K}_{2} \mathrm{CO}_{3}$ increases.

Fig. 5 shows a typical TICC of the DEE-soluble fraction of ligninoil samples obtained in the runs containing lignin in the feed. The structure of the identified compounds is also reported, along with number labels referring to Table 8; this reports the mass fractions of these compounds together with overall values including, and excluding, phenol. When different isomers are compatible with a peak, the structure reported in Fig. 5 is an example of one of the possible isomers. 
Table 7

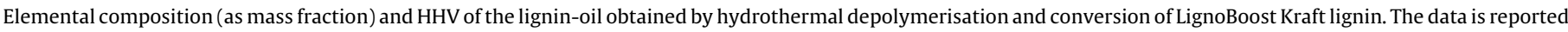
on a dry lignin-oil basis, together with available uncertainties ( $95 \%$ confidence interval), relative (rel.) or absolute (abs.). Oxygen is calculated by difference.

\begin{tabular}{|c|c|c|c|c|c|}
\hline Elemental composition (\%) & A & B & $\mathrm{C}$ & $\mathrm{D}$ & $\mathrm{U}$ \\
\hline C & 74.6 & 74.2 & 74.9 & 74.8 & $1.1 \%$ (rel.) \\
\hline $\mathrm{H}$ & 6.9 & 6.9 & 6.6 & 6.5 & $4 \%$ (rel.) \\
\hline $\mathrm{N}$ & $<0.1$ & $<0.1$ & $<0.1$ & - & $20 \%$ (rel.) \\
\hline S & 0.37 & 0.38 & 0.38 & 0.29 & $16 \%$ (rel.) \\
\hline $\mathrm{Cl}$ & $<0.01$ & $<0.01$ & $<0.01$ & $<0.01$ & - \\
\hline Ash & 1.0 & 2.1 & 2.8 & 3.5 & - \\
\hline $\mathrm{O}$ & 17 & 16 & 15 & 15 & - \\
\hline $\mathrm{Na}$ & $<0.01$ & $<0.01$ & 0.01 & $<0.01$ & - \\
\hline K & 0.46 & 1.00 & 1.60 & 1.90 & - \\
\hline $\mathrm{HHV}(\mathrm{MJ} / \mathrm{kg})$ & 31.93 & 31.83 & 31.90 & 31.86 & 0.16 (abs.) \\
\hline
\end{tabular}

The DEE-soluble fraction of lignin-oil contains a large amount of 1-ring aromatic compounds. Besides phenol (from 13\% to 16\%), the compounds with higher mass fractions based on dry ligninoil are anisoles (from $2.4 \%$ to $9.4 \%$ ), alkylphenols (from $4.3 \%$ to $6.4 \%$ ), guaiacols (from $2 \%$ to $3 \%$ ) and catechols (below $1 \%$ ). Some 2-ring phenolic compounds (phenolic dimers), with a C6-C1-C6 or $\mathrm{C} 6-\mathrm{C} 2-\mathrm{C} 6$ structure, are also found. Most of the compounds in the DEE-soluble fraction of lignin-oil are the same as in the aqueous phase, with distribution coefficients depending on their being hydrophilic or hydrophobic in nature. For example, catechol is relatively more abundant in the aqueous phase whereas anisole is concentrated in the oil. In addition, some compounds not found in the aqueous phase are identified in the DEE-soluble fraction of lignin-oil, as in the case of alkylanisoles, 1-ring phenolic compounds with propyl side chains, ethylcresol, acetylphenol and two compounds with 3 rings (see Fig. 5). The total mass fraction of DEEsoluble compounds in lignin-oil increases with $\mathrm{K}_{2} \mathrm{CO}_{3}$; with regard to specific classes of compounds, the amount of anisoles, alkylphenols and catechols increases whilst that of the guaiacols decreases (see Table 9). These trends are also found for the water-soluble compounds in the aqueous phase.

\subsection{Product yields and carbon balances}

Product yields are calculated taking three different products into consideration: dry lignin-oil (OIL), water-soluble organics in the acidified aqueous phase (WSO) and char (CHAR). The corresponding yields $(Y)$ are defined here as the mass of phenol-free products relative to the mass of dry lignin fed into the system. The calculations are made assuming that the average rate of char formation during the entire run (i.e. start-up, steady-state and cooling down) is equal to the rate of formation at steady-state. The yield of the main classes of 1-ring aromatic compounds is also calculated, taking into account the quantities found in both the aqueous and the oil phase.

Table 10 shows that the yield of dry lignin-oil is approximately constant around 70\%. However, the amount of water-soluble organics found in the acidified aqueous phase varies from $9 \%$ to $11 \%$ of dry lignin, with a trend showing a slight increase as the mass fraction of $\mathrm{K}_{2} \mathrm{CO}_{3}$ increases. As far as char deposited on the catalyst is concerned, this fraction is about $20 \%$ of the dry lignin fed to the system. In the case of the conversion of lignin to 1-ring aromatic compounds (see Table 11), the total yield increases remarkably

Table 8

The compounds identified in the DEE-soluble fraction of the lignin-oil. Mass fractions (\%) based on dry lignin-oil are reported for each of the runs with lignin in the feed.

\begin{tabular}{|c|c|c|c|c|c|}
\hline & Compound & A & B & C & $\mathrm{D}$ \\
\hline 1 & Anisole & 2.103 & 4.412 & 4.414 & 8.170 \\
\hline 2 & Phenol & 13.428 & 14.559 & 12.797 & 16.220 \\
\hline 3 & 2-Methylanisole & 0.064 & 0.147 & 0.173 & 0.270 \\
\hline 4 & 4-Methylanisole & 0.133 & 0.330 & 0.409 & 0.652 \\
\hline 5 & o-Cresol & 0.936 & 1.155 & 1.158 & 1.306 \\
\hline 6 & $\mathrm{~m} / \mathrm{p}-$ Cresol $^{\mathrm{a}}$ & 1.202 & 1.809 & 1.923 & 2.257 \\
\hline 7 & Guaiacol & 1.969 & 1.729 & 1.344 & 1.818 \\
\hline 8 & 4-Ethylanisole & 0.087 & 0.189 & 0.238 & 0.323 \\
\hline 9 & 2-Ethylphenol & 0.538 & 0.563 & 0.511 & 0.541 \\
\hline 10 & Dimethylphenol & 0.251 & 0.361 & 0.402 & 0.507 \\
\hline 11 & 2-Acetylphenol & 0.102 & 0.153 & 0.156 & 0.238 \\
\hline 12 & 4-Ethylphenol & 1.006 & 1.241 & 1.200 & 1.363 \\
\hline $13-14$ & Methylguaiacols & 0.514 & 0.469 & 0.399 & 0.529 \\
\hline 15 & Catechol & 0.182 & 0.206 & 0.181 & 0.275 \\
\hline 16 & Ethylcresol & 0.096 & 0.128 & 0.144 & 0.160 \\
\hline 17 & Propylphenol & 0.231 & 0.281 & 0.288 & 0.301 \\
\hline 18 & 4-Ethylguaiacol & 0.571 & 0.276 & 0.204 & 0.249 \\
\hline 19 & 4-Methylcatechol & 0.196 & 0.202 & 0.122 & 0.282 \\
\hline 20 & Syringol $^{\mathrm{b}}$ & - & - & - & - \\
\hline 21 & 4-Propylguaiacol & 0.156 & 0.069 & 0.050 & 0.061 \\
\hline 22 & 4-Ethylcatechol & 0.213 & 0.167 & 0.113 & 0.245 \\
\hline 23 & 9H-Xanthene & 0.232 & 0.169 & 0.100 & 0.449 \\
\hline $24-28$ & Phenolic dimers & 1.786 & 2.015 & 1.747 & 2.614 \\
\hline 29 & Isopropyl-methyl-phenanthrene & 0.367 & 0.322 & 0.242 & 0.212 \\
\hline \multicolumn{2}{|c|}{ Total mass fraction including phenol } & 26.36 & 30.95 & 28.32 & 39.04 \\
\hline \multicolumn{2}{|c|}{ Total mass fraction excluding phenol } & 12.94 & 16.39 & 15.52 & 22.82 \\
\hline
\end{tabular}

\footnotetext{
a $\mathrm{p}$-Cresol and m-Cresol elute together.
}

b Internal standard. 


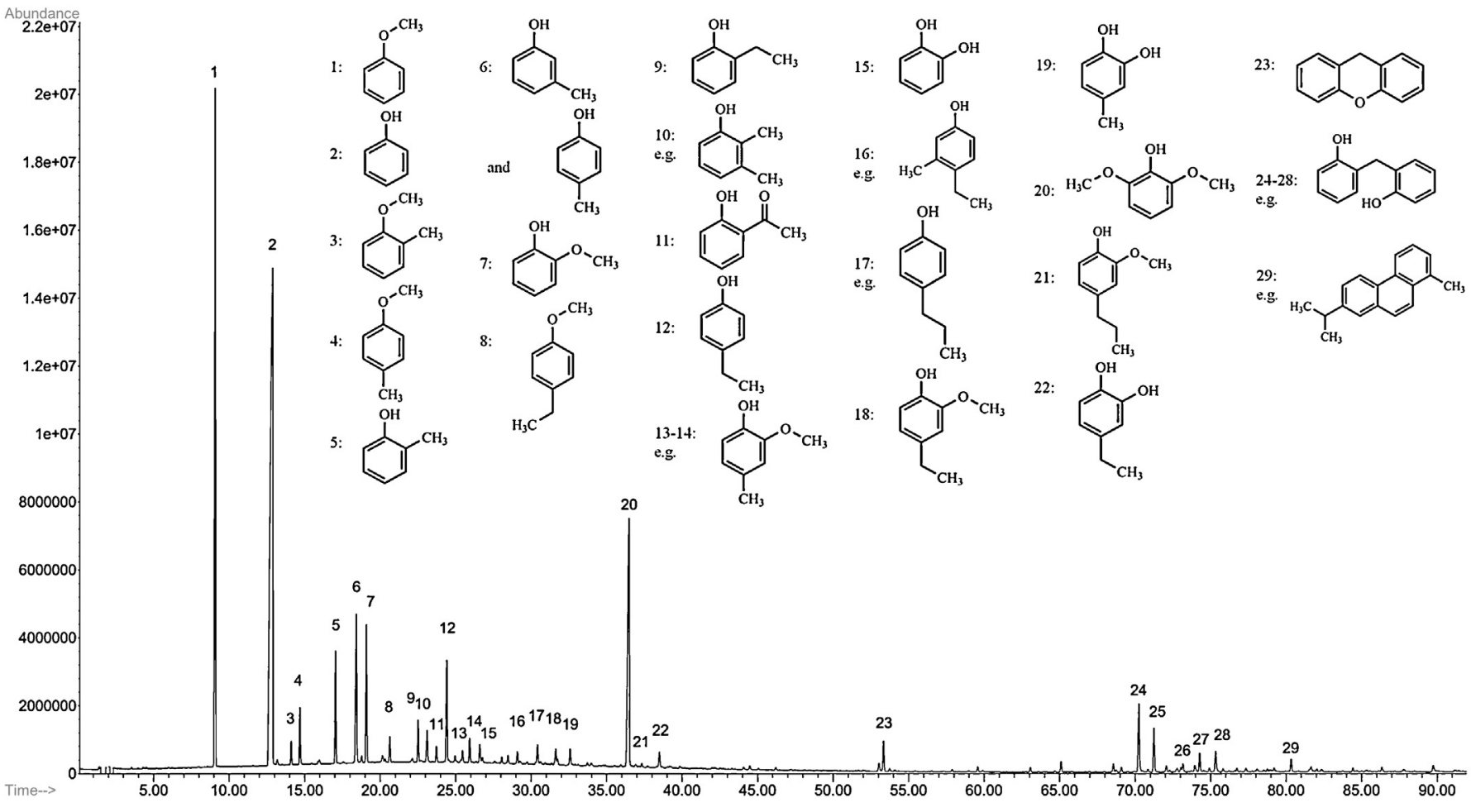

Fig. 5. Typical TICC of the DEE-soluble fraction of lignin-oil (sample from Run A). Peak 20 is the internal standard (syringol).

Table 9

Mass fractions (\%) of the main classes of compounds of the DEE-soluble fraction of the lignin-oil. Mass fractions are based on dry lignin-oil and are reported for each run with lignin in the feed.

\begin{tabular}{lrrrr}
\hline Class & \multicolumn{1}{c}{ A } & \multicolumn{1}{c}{ B } & \multicolumn{1}{c}{ C } & \multicolumn{1}{c}{ D } \\
\hline Anisoles & 2.39 & 5.08 & 5.23 & 9.42 \\
Phenol & 13.43 & 14.56 & 12.80 & 16.22 \\
Alkylphenols & 4.26 & 5.54 & 5.63 & 6.44 \\
Guaiacols & 3.21 & 2.54 & 2.00 & 2.66 \\
Catechols & 0.59 & 0.58 & 0.42 & 0.80 \\
Phenolic dimers & 1.79 & 2.02 & 1.75 & 2.61 \\
\hline
\end{tabular}

Table 10

Yields of lignin-oil $\left(Y_{O I L}\right)$, water-soluble organics in the acidified aqueous phase $\left(Y_{\text {WSO }}\right)$ and char $\left(Y_{C H A R}\right)$, calculated on phenol-free products on a dry lignin basis.

\begin{tabular}{llcl}
\hline & $Y_{\text {OIL }}(\%)$ & $Y_{\text {WSO }}(\%)$ & $Y_{\text {CHAR }}(\%)$ \\
\hline A & 70.2 & 8.7 & 20.6 \\
B & 69.4 & 8.9 & 17.8 \\
C & 72.2 & 9.7 & 20.7 \\
D & 70.9 & 10.8 & 17.2 \\
\hline
\end{tabular}

\section{Table 11}

Yield (\%) of different classes of 1-ring aromatic compounds produced in the depolymerisation and conversion of lignin, calculated on a dry lignin basis.

\begin{tabular}{|c|c|c|c|c|}
\hline Class & A & $\mathrm{B}$ & $\mathrm{C}$ & $\mathrm{D}$ \\
\hline Anisoles & 2.0 & 4.1 & 4.3 & 8.6 \\
\hline Alkylphenols & 6.3 & 7.7 & 8.1 & 9.2 \\
\hline Guaiacols & 4.4 & 3.3 & 2.6 & 2.9 \\
\hline Catechols & 4.1 & 4.4 & 5.0 & 6.0 \\
\hline Total 1-ring aromatic compounds ${ }^{a}$ & 16.9 & 19.8 & 20.4 & 27.1 \\
\hline
\end{tabular}

a These include 2-acetylphenol, 3-methoxycatechol and salicylic acid.

with $\mathrm{K}_{2} \mathrm{CO}_{3}$, varying from approx. $17 \%$ to more than $27 \%$. The larger relative increase is found for anisoles in particular (from $20 \mathrm{~g} / \mathrm{kg}$ to $86 \mathrm{~g} / \mathrm{kg}$ ), while alkylphenols and catechols increase moderately; the maximum yield of guaiacols is to be found at the lowest mass fraction of $\mathrm{K}_{2} \mathrm{CO}_{3}$.
From the data reported in Tables 1-3 and Tables 6-7, the ratio of the potassium ending up in the wet oil to the potassium entering the system was calculated. It was found that this value decreases from 9.1\% to $7.0 \%$ as $\mathrm{K}_{2} \mathrm{CO}_{3}$ increases. This indicates that some potassium salts may precipitate during the process. This aspect should be further investigated in the development of the downstream processing of the oil. The total carbon balance is also calculated, i.e. including phenol and inorganic carbon. In these calculations the carbon content of char is assumed to be the same as that of dry lignin. It is found that the sum of the output and the accumulated carbon accounts from $95 \%$ to $101 \%$ of the carbon input. On the whole, these results show that a very reliable carbon balance is obtained in all runs.

\section{Conclusions}

The feasibility of the catalytic conversion of LignoBoost Kraft lignin in near-critical water, leading to water-soluble chemicals and oil, is demonstrated in this study. The yield of water-soluble lignin-derived compounds found in the acidified aqueous phase is approximately $10 \%$ of the dry lignin fed to the system under the conditions used in this series of experimental runs. The GC-MS analysis shows that these compounds are mainly cresols, guaiacols and catechols, with alkyl side chains of the methyl and ethyl type only. As far as the oil is concerned, the yield of dry lignin-oil is approximately $70 \%$ with respect to the dry lignin fed into the system. The oil is partially deoxygenated with respect to the lignin fed to the system; the heat value of the oil is approximately constant and equal to $32 \mathrm{MJ} / \mathrm{kg}$. The increase in the heat value from the dry lignin to the dry oil is, on average, about $15 \%$ of the original value. The mass fraction of sulphur is also reduced greatly: on average down from $1.85 \%$ to $0.36 \%$. The ash content of the oil increases with the mass fraction of $\mathrm{K}_{2} \mathrm{CO}_{3}$ in the system. The DEE-soluble fraction of the oil accounts for approximately 30\% of the whole oil. The GC-MS analysis of this fraction basically shows the same compounds as in the aqueous phase, with the relative distribution 
depending on whether they are hydrophilic or hydrophobic in nature. In addition, some compounds not found in the aqueous phase, such as alkylanisoles, alkylphenols with propyl side chains and 3-ring aromatic compounds, are identified in the oil.

Regarding the conversion of dry lignin into 1-ring aromatic compounds, it is found that the total yield increases remarkably (from $169 \mathrm{~g} / \mathrm{kg}$ to $271 \mathrm{~g} / \mathrm{kg}$ ) as the mass fraction of $\mathrm{K}_{2} \mathrm{CO}_{3}$ in the feed is increased from $0.4 \%$ to $2.2 \%$. Furthermore, there is a remarkable increase in the yield of anisoles, together with moderate increases in the yields of alkylphenols and catechols, as the amount of $\mathrm{K}_{2} \mathrm{CO}_{3}$ increases. At the highest mass fraction of $\mathrm{K}_{2} \mathrm{CO}_{3}$ used in this study, $1 \mathrm{~kg}$ of dry lignin gives $86 \mathrm{~g}$ anisoles, $92 \mathrm{~g}$ alkylphenols, $29 \mathrm{~g}$ guaiacols and $60 \mathrm{~g}$ catechols. Under this operating condition anisole is the most abundant product, with a yield of $75 \mathrm{~g} / \mathrm{kg}$.

\section{Acknowledgements}

This work is supported by grants from Chalmers Energy Initiative - LignoFuel Project, Metso Power AB, The Swedish Energy Agency and Ångpanneförenings Forskningsstiftelse. Our thanks go to Lars Nordstierna for the NMR analysis and Bengt Erichsen, Lena Elisabeth Fogelquist and Tommy Friberg for their technical contributions to the experiments.

\section{References}

[1] P. Tomani, The LignoBoost process, Cellulose Chemistry and Technology 44 (2010) 53-58.

[2] H. Theliander, Withdrawing lignin from black liquor by precipitation, filtration and washing, in: First Nordic Wood Biorefinery Conference, 2008, pp. 36-42.

[3] G. Gellerstedt, G. Henriksson, Lignins: major sources, structure and properties, in: M.N. Belgacem, A. Gandini (Eds.), Monomers, Polymers and Composites from Renewable Resources, Elsevier, Amsterdam, 2008, pp. 201-224.

[4] A. Vigneault, D.K. Johnson, E. Chornet, Base-catalyzed depolymerization of lignin: separation of monomers, Canadian Journal of Chemical Engineering 85 (2007) 906-916.

[5] M.P. Pandey, C.S. Kim, Lignin depolymerization and conversion: a review of thermochemical methods, Chemical Engineering and Technology 34 (2011) 29-41.
[6] M. Saisu, T. Sato, M. Watanabe, T. Adschiri, K. Arai, Conversion of lignin with supercritical water-phenol mixtures, Energy and Fuels 17 (2003) 922-928

[7] K. Okuda, M. Umetsu, S. Takami, T. Adschiri, Disassembly of lignin and chemical recovery - rapid depolymerization of lignin without char formation in water-phenol mixtures, Fuel Processing Technology 85 (2004) 803-813.

[8] Z. Fang, T. Sato, R.L. Smith Jr., H. Inomata, K. Arai, J.A. Kozinski, Reaction chemistry and phase behavior of lignin in high-temperature and supercritical water, Bioresource Technology 99 (2008) 3424-3430.

[9] T.M. Aida, T. Sato, G. Sekiguchi, T. Adschiri, K. Arai, Extraction of Taiheiyo coal with supercritical water-phenol mixtures, Fuel 81 (2002) 1453-1461.

[10] J.E. Miller, L.R. Evans, J.E. Mudd, K.A. Brown, Batch microreactor studies of lignin depolymerization by bases: 2 . Aqueous solvents, Sandia National Laboratories Report, SAND2002-1318, 2002.

[11] G. Unkelbach, D. Schmiedl, R. Schweppe, T. Hirth, Catalyzed hydrothermal degradation of lignins from biorefineries to aromatic compounds, in: 11th European Workshop on Lignocellulosics and Pulp, 2010, pp. 57-60.

[12] D. Schmiedl, G. Unkelbach, J. Graf, R. Schweppe, Studies in catalyzed hydrothermal degradation processes on sulphur-free lignin and extractive separation of aromatic SYNTHONs, in: Second Nordic Wood Biorefinery Conference, 2009, pp. 189-196.

[13] J.-M. Lavoie, W. Baré, M. Bilodeau, Depolymerization of steam-treated lignin for the production of green chemicals, Bioresource Technology 102 (2011) 4917-4920.

[14] S. Karagöz, T. Bhaskar, A. Muto, Y. Sakata, T. Oshiki, T. Kishimoto, Low-temperature catalytic hydrothermal treatment of wood biomass: analysis of liquid products, Chemical Engineering Journal 108 (2005) $127-137$.

[15] S. Karagöz, T. Bhaskar, A. Muto, Y. Sakata, Hydrothermal upgrading of biomass: effect of $\mathrm{K}_{2} \mathrm{CO}_{3}$ concentration and biomass/water ratio on products distribution, Bioresource Technology 97 (2006) 90-98.

[16] T. Bhaskar, A. Sera, A. Muto, Y. Sakata, Hydrothermal upgrading of wood biomass: influence of the addition of $\mathrm{K}_{2} \mathrm{CO}_{3}$ and cellulose/lignin ratio, Fuel 87 (2008) 2236-2242

[17] K. Andersen, Gasification process, DE 3806732 A1, 1989.

[18] K. Andersen, Gasification process, EP 0402405 B1, 1990.

[19] A. Hammerschmidt, N. Boukis, E. Hauer, U. Galla, E. Dinjus, B. Hitzmann, T. Larsen, S.D. Nygaard, Catalytic conversion of waste biomass by hydrothermal treatment, Fuel 90 (2011) 555-562.

[20] S.S. Toor, L. Rosendahl, M.P. Nielsen, M. Glasius, A. Rudolf, S.B. Iversen, Continuous production of bio-oil by catalytic liquefaction from wet distiller's grain with solubles (WDGS) from bio-ethanol production, Biomass and Bioenergy 36 (2012) 327-332.

[21] J. Waltersson, The metal binding properties of Kraft lignin (Degree Thesis), Mälardalens Högskola Eskilstuna Västerås, Sweden, 2009. 